
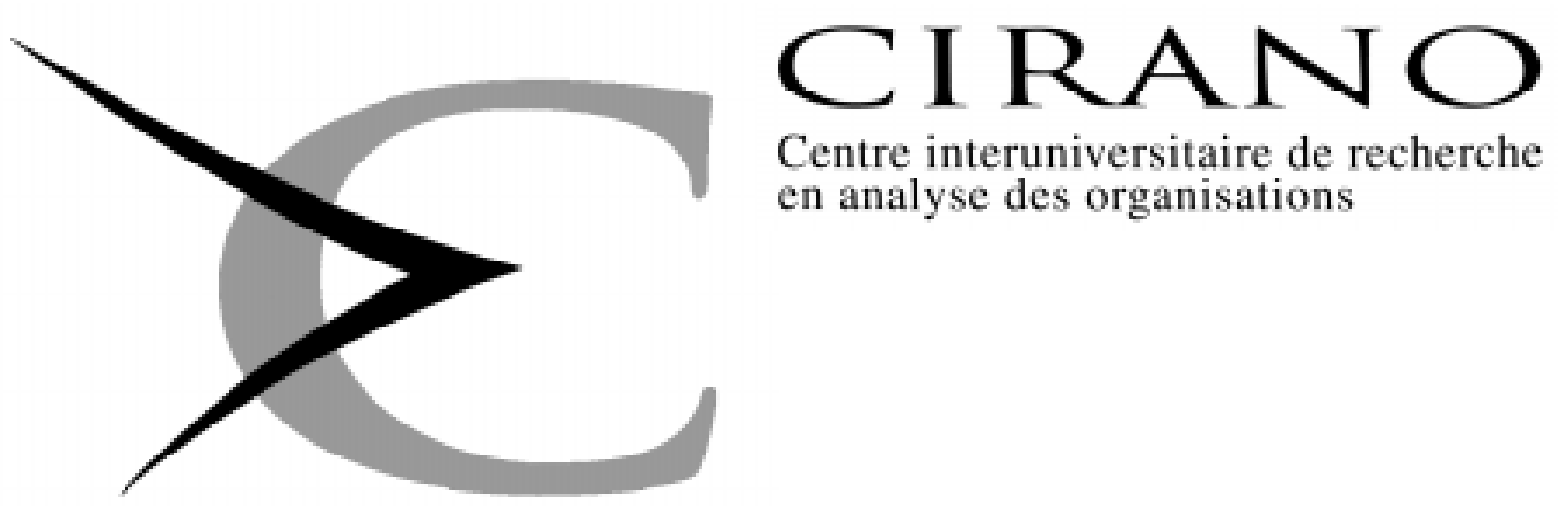

Centre interuniversitaire de recherche en analyse des organisations

Série Scientifique

Scientific Series

97s-28

Are Underground Workers

More Likely To Be

Underground Consumers?

Bernard Fortin, Guy Lacroix,

Claude Montmarquette 


\section{CIRANO}

Le CIRANO est une corporation privée à but non lucratif constituée en vertu de la Loi des compagnies du Québec. Le financement de son infrastructure et de ses activités de recherche provient des cotisations de ses organisations-membres, d'une subvention d'infrastructure du ministère de l'Industrie, du Commerce, de la Science et de la Technologie, de même que des subventions et mandats obtenus par ses équipes de recherche. La Série Scientifique est la réalisation d'une des missions que s'est données le CIRANO, soit de développer l'analyse scientifique des organisations et des comportements stratégiques.

CIRANO is a private non-profit organization incorporated under the Québec Companies Act. Its infrastructure and research activities are funded through fees paid by member organizations, an infrastructure grant from the Ministère de l'Industrie, du Commerce, de la Science et de la Technologie, and grants and research mandates obtained by its research teams. The Scientific Series fulfils one of the missions of CIRANO: to develop the scientific analysis of organizations and strategic behaviour.

\section{Les organisations-partenaires / The Partner Organizations}

-École des Hautes Études Commerciales

-École Polytechnique

-McGill University

-Université de Montréal

-Université du Québec à Montréal

-Université Laval

-MEQ

-MICST

-Avenor

-Banque Nationale du Canada

-Bell Québec

-Caisse de dépôt et placement du Québec

-Fédération des caisses populaires Desjardins de Montréal et de l'Ouest-du-Québec -Hydro-Québec

-Raymond, Chabot, Martin, Paré

-Scetauroute

-Société d'électrolyse et de chimie Alcan Ltée

-Téléglobe Canada

-Ville de Montréal

Ce document est publié dans l'intention de rendre accessibles les résultats préliminaires de la recherche effectuée au CIRANO, afin de susciter des échanges et des suggestions. Les idées et les opinions émises sont sous l'unique responsabilité des auteurs, et ne représentent pas nécessairement les positions du CIRANO ou de ses partenaires.

This paper presents preliminary research carried out at CIRANO and aims to encourage discussion and comment. The observations and viewpoints expressed are the sole responsibility of the authors. They do not necessarily represent positions of CIRANO or its partners.

ISSN 1198-8177 


\title{
Are Underground Workers More Likely To Be Underground Consumers?*
}

\author{
Bernard Fortin ${ }^{\dagger}$, Guy Lacroix ${ }^{\ddagger}$ Claude Montmarquette ${ }^{\S}$
}

Résumé / Abstract

\begin{abstract}
Cet article étudie les effets du travail au noir sur le niveau des achats au noir des individus. On montre qu'il peut se décomposer en un effet de réseau, un effet de non-séparabilité et un effet revenu. Notre analyse empirique utilise des micro-données tirées d'une enquête réalisée au Québec pour l'année 1993. La méthode des moments généralisés nous permet de tenir compte de la censure et des erreurs de mesure sur la variable dépendante ainsi que de l'endogénéité des variables d'offre de travail qui conditionnent les décisions de consommation. Selon nos résultats, une hausse de l'offre de travail au noir accroît de façon importante le niveau des dépenses au noir. Cet effet amplifie l'impact des politiques de taxation et de contrôle fiscal sur la taille de l'économie souterraine.

This paper investigates the effect of working in the underground sector on the level of individual underground expenditures. We show that it can be decomposed into a network effect, a non-separability effect and an income effect. Our empirical analysis uses micro data from a randomized survey conducted in the province of Québec for 1993. GMM methods allow us to take into account censoring and measurement error on the dependent variable as well as the possible endogeneity of the conditioning labor supply variables. We find that an increase in the underground labor supply has a strong positive effect on the level of underground expenditures. This relationship amplifies the impact of tax policy and of the enforcement system on the size of the underground economy.
\end{abstract}

Mots Clés : $\quad$ Consommation au noir, travail au noir, séparabilité, impact des politiques, estimations par la méthode des moments généralisés

Keywords : Underground consumption, underground work, separability, policy impacts, GMM estimations

\footnotetext{
* Correspondence Address: Bernard Fortin, CIRANO, 2020 University Street, 25th floor, Montréal, Qc, Canada H3A 2A5 Tel: (514) 985-4027 Fax: (514) 985-4039 e-mail: fortinb@ cirano.umontreal.ca Financial support from the Department of Finance Canada and CIRANO is gratefully acknowledged. We thank Louis Trottier for excellent research assistance and Gaétan Garneau and François Raymond for their help in constructing the data set. We are also grateful to Thomas Lemieux, Pascal St-Amour and Bruce Shearer for very helpful discussions.

† Université Laval and CIRANO

‡ Université Laval and CIRANO

§ Université de Montréal and CIRANO
} 


\section{Introduction}

It is widely recognized that one major effect of income taxation is to stimulate activities in the so-called underground or irregular economy. Recently, a number of microeconometric studies have attempted to estimate the impact of income tax policies on hours of work in the irregular sector. Lacroix and Fortin (1992) have estimated a system of simultaneous labor supply equations in the regular and irregular sectors based on a tax evasion theoretical framework [e.g., see Sandmo (1981) and Cowell (1985)]. They showed that an increase in marginal income tax rates leads to increased hours in the irregular sector and to reduced hours in the regular sector, for those participating in both sectors. Lemieux, Fortin and Fréchette (LFF, 1994) estimated a model à la Gronau (1977) of the allocation of time between regular and irregular sectors. They concluded that taxes distort labor-market activities away from the regular sector to the underground economy. The distortion was found to be particularly large for specific groups of the population such as welfare claimants.

While these studies provide some information on the supply side of the irregular sector, surprisingly little is known about the factors influencing the demand for goods and services produced in that sector. ${ }^{1}$ However, ignoring the demand side may produce dramatically biased estimates of responses to tax or enforcement policies. Thus, one can expect that individuals working in the underground sector are more likely to be underground consumers than individuals who do not work in the underground sector, ceteris paribus. This would generate a positive correlation between changes in the supply and changes in the demand of goods and services in the underground sector. In this event, one expects that an increase in marginal tax rates, which encourages more people to work in the underground sector, will have a larger impact on the size of the underground sector than otherwise. ${ }^{2}$ Conversely, the negative effects of enforcement policies (e.g., more severe controls or larger penalties on tax evaders) on the importance of the underground sector will be enhanced.

There are a number of reasons why individual hours of work and purchases in the underground sector are likely to be positively related

\footnotetext{
${ }^{1}$ One exception is Pestieau (1985) who provided a logit estimation of the determinants of the demand for undeclared services in Belgium, based on survey data. In particular, his results show that it increases with age and income. However, he does not take into account the endogeneity of income and his model is not based on a utility-theoretic approach.

${ }^{2}$ Of course, in a general equilibrium framework, the analysis would also have to take into account other factors such as the composition of additional government expenditures generated by the taxes increase, changes in relative wages and prices, income effects, etc. [see Cowell (1990)].
} 
(even after controlling for the level of disposable income and for other observable characteristics). A first reason is that individuals working in the underground sector may have better access to that sector's output [Kesselman (1989)]. It is thus possible that underground workers benefit from information on the availability of goods and services produced in the irregular sector. This "network effect" is likely to lower search costs and to induce these workers to increase their purchases of underground commodities. Second, preferences over goods and services in the underground sector may be non-separable from labor supply in that sector. A familiar example is the demand for undeclared housework services or home improvement for those underground workers who have few hours available to spend on these activities. Third, the income effect of working in the underground sector may increase the demand for some undeclared goods and services (e.g., baby-sitting services). However, the income effect may also decrease the demand for some (inferior) undeclared commodities in favor of commodities produced in the regular sector. Fourth, some people may be engaged in barter of goods and services produced informally for home consumption [Kesselman (1989)]. Finally, unobservable individual characteristics may influence both consumption and labor supply in the underground sector in the same direction (e.g., low level of morality, dissatisfaction with government intervention, culture of tax evasion, etc.).

This paper provides strong evidence in support of a positive correlation between purchases of irregular commodities and hours of work in the irregular sector. Our data show that workers involved in the underground sector spend six times as much on irregular commodities than those who are not involved. Moreover, the econometric analysis presented below concludes that hours of work in the underground sector have a strong effect on the consumption of irregular goods and services.

More generally, this paper provide estimates of the demand for goods and services in the underground sector using micro data from a recent survey conducted in the Province of Quebec. ${ }^{3}$ The survey was conducted in 1994 and includes over 5,000 adults 18 years and over. It is similar to another survey conducted in 1986 (see LFF, 1994) but covers a much wider geographic area.

For estimation purposes, we include hours of work in both the regular and irregular sectors as explanatory variables while allowing for possible endogeneity. ${ }^{4}$ This conditional approach, developed by Browning and

\footnotetext{
${ }^{3}$ See Fortin et al. (1996) for a description of the data set.

${ }^{4}$ Due to lack of observations, we could not estimate a system of demand for declared and undeclared goods and services. Instead, we estimate an equation for total expenditures in the underground sector, acknowledging some aggregation problems.
} 
Meghir (1991), has many advantages over the standard unconditional approach in which labor supply and commodity demand functions are estimated simultaneously. In particular, we do not have to specify the equations for the labor supply in each sector since our estimates are not affected by the choice of these specifications. This also implies that we do not have to estimate the impact of the income tax schedules on labor supplies, which is usually a highly complex task. Furthermore, we do not have to estimate a model in which the individual has some influence on the consumer price of undeclared goods, due to the presence of a network effect which is dependent on time worked in the underground sector. This is so because our estimates are conditional on hours worked in the irregular sector. Finally, including hours of work in each sector as explanatory variables is required to get consistent estimates of the Engel curve for irregular expenditures, so long as the latter are affected by these variables.

The model is estimated using the Generalized Method of Moments (GMM) applied to a censored normal regression model with endogenous explanatory variables. Our approach extends Stapleton and Young's (1984) estimators based on either the expectation function or the conditional expectation function for uncensored observations on the dependent variable. The main advantage of these estimators over conventional tobit estimators is that they are robust to measurement error on the positive values of the dependent variable. Indeed, survey data on the reported positive amount of undeclared goods and services are likely to be subject to serious measurement problems. For instance, individuals may be willing to report that they have purchased irregular commodities, while being reluctant (or unable) to report the exact amount actually bought.

In Section 2, we discuss the survey and provide descriptive statistics of our sample data in support of our hypothesis. In Section 3, we provide a simple theoretical model of the demand for irregular goods and services that takes into account the network effect. Section 4 discusses the econometric methodology used to estimate the model. Section 5 presents the empirical variables and reports our main econometric findings. In Section 6, we consider some policy simulations. Section 7 concludes.

\section{The Survey and Descriptive Results}

Obtaining reliable micro data about sensitive behavioral aspects requires the use of carefully tested methods. Accordingly, the data used in this

Moreover, price effects could not be estimated since we use cross-sectional data and we have no information on prices in the underground sector. 
paper, which are derived from a survey conducted in spring 1994 for the year 1993, follows very closely the approach described in LFF. Both our questionnaire and sample design are largely inspired by the ones they used. In addition to traditional questions on socioeconomic characteristics, our questionnaire includes numerous questions on underground labor activities and about expenditures on commodities in the underground sector. The term "underground" (that is never used in the survey) refers to (mostly legal) economic activities that generate income hidden to the tax authorities. The questionnaire also includes questions on labor activities in the regular sector, on nonwage income and on perceptions and attitudes of respondents towards taxes and irregular activities.

As regards the sample design, 2940 households were sampled in the Province of Quebec. These households yielded 5132 individuals 18 years and over, compared to 2134 in LFF. While the survey described by LFF was limited to the region of Quebec City, three regions were covered in our survey: the metropolitan areas of Quebec City (2 014 individuals), Montreal (2 035 individuals) and the region of "Bas StLaurent" (1 093 individuals). Montreal is the most industrialized region of the Province and by far the most populated. Quebec City hosts the provincial government, and the "Bas St-Laurent" region is an amalgam of small villages and cities in a semi-urban or rural environment. The sample methodology is based on the random-cluster approach used by Statistics Canada in its Labor Force Survey.

The survey was conducted by a well known polling agency in Quebec (Léger \& Léger). Interviewers were trained to emphasize the strictly scientific purpose of the survey and to highlight the anonymous and confidential character of the collected data. Each respondent who accepted to fill a questionnaire received an amount of $\$ 5$ (Can). The respondents were asked to put the filled questionnaire in a sealed envelope that was picked up a day later.

Our sample design produced an overall rate of response (53\%) very closed to the one reported in LFF (51.7\%). As discussed in detail in Fortin et al. (p. 21-23, 1996), the socioeconomic characteristics of our sample are, in general, similar to those observed in the Statistics Canada's Survey of Consumer Finance (SCF) for 1993 and for the same regions. While the respondents of our survey are slightly younger and more educated than those from the SCF, the proportion of men and women are similar in both surveys. Moreover, the industrial distribution of jobs held by respondents are also comparable. These results tend 
to confirm the representativeness of our sample. Fortin et al. (1994) also provides a number of tests that corroborate the reliability of the data. ${ }^{5}$

Table 1 provides descriptive statistics on the relationship between purchases of commodities in the underground economy and labor status vis-à-vis the underground and regular labor markets. The sample we utilize excludes two-parent households since our model of demand for irregular commodities does not take into account interactions between members within the household. ${ }^{6}$ The sample includes 1569 individuals of which 236 (that is, 15\%) purchased irregular commodities in 1993 (see the last line of Table 1). The average total purchases of irregular commodities by individuals who did not work in the underground sector (1 440 individuals) is $\$ 136$ (Can), while it amounts to $\$ 817$ for the 129 individuals who worked in the underground sector [see columns (1) and (2)]. Thus, the total purchases of underground commodities by underground workers were about 6 times larger, on average, than those made by the individuals who did not work in the underground sector. We now focus on the subsample of individuals who purchased a positive amount of irregular commodities (the restricted sample). The 53 individuals who worked in the underground sector spent 1.85 times as much on irregular goods and services than those who did not ( $\$ 1990$ vs $\$ 1071$ ).

In comparison, the level of expenditures in the underground sector is much less related to hours worked in the regular sector. Indeed, the average total expenditures on irregular commodities is $\$ 162$ for the 577 individuals who did not work in the regular sector and amounts to $\$ 209$ for the 992 individuals who did. Thus, the ratio in their case is only 1.29. Moreover, amongst the consumers of irregular commodities, the average level of expenditures for the individuals who did not work in the regular market (62) is $\$ 1507$ while it amounts to $\$ 1196$ for the 174 individuals who did (a difference of $26 \%$, that time, in favor of those who did not wok in the regular sector).

While informative, this descriptive analysis must be interpreted with care since other variables that may affect the level of purchases are not controlled (e.g., gender or the level of disposable income). Furthermore, one must take into account the fact that hours of work in each sector are endogenous variables. Finally, expenditures on goods and services in the underground sector is a censored variable and this must also be con-

\footnotetext{
${ }^{5}$ They also present a descriptive analysis of the results of the survey as well as a comparison of the underground economy in the Province of Quebec in 1985 and 1993, based on extrapolations from data on the Region of Quebec in the two surveys.

${ }^{6}$ See Browning et al. (1994) for a collective model of the intra-household allocation of consumption. Estimating a model of the demand for irregular commodities along these lines is beyond the scope of this paper.
} 
sidered in the econometric analysis. The next sections aim at presenting and estimating a model of demand for irregular goods and services that address these various issues.

\section{A Model of Demand for Irregular Com- modities}

Our model is based on the standard tax evasion model with endogenous variables [see Cowell (1985)]. To simplify the presentation, we limit the analysis to income tax evasion. ${ }^{7}$ We introduce a network effect into the model by assuming that individuals face a marginal cost of access to irregular goods and services which is a function of a set of exogenous variables, and is decreasing with the level of hours worked in the underground sector. ${ }^{8}$ The basic argument here is that a side effect of working in the underground economy is to provide more information about sellers in the underground markets and thus to reduce the cost of access to irregular commodities. Our model also allows for imperfect substitution between regular and irregular goods and services. Even where regular and irregular sectors appear to produce the same commodity, regular output is likely to be preferred to irregular one on account of better reputation, warranty policy, follow-up service, return policy, etc.

On the income side, working in the irregular labor market involves a risk of being caught and having to pay a penalty that is a positive function of unpaid income taxes. However the individual has the possibility of reducing the probability of being detected by investing resources to hide his irregular working activities. In our model, the risk is limited to the supply side of the underground economy, since, as a buyer, an individual is not responsible under current law for unpaid income or consumption taxes. ${ }^{9}$

Assume two states of nature. With probability $p \in[0,1]$, an individual is audited by the tax authorities and must pay a penalty on any unpaid income taxes. With probability $1-p$, he is not audited and avoids

\footnotetext{
${ }^{7}$ Sales taxes such as the federal Goods and Services Tax (GST) and the provincial Taxe de Vente du Québec (TVQ) are not explicitly modeled since their tax rates are fixed in our cross-sectional sample.

${ }^{8} \mathrm{An}$ earlier version of the model also allowed for a fixed effect of participating in the underground sector on the cost of access to irregular commodities. However this effect was found not to be statistically significant.

${ }^{9}$ One could generalize the model to account for the fact that an individual who hires workers (thus a buyer of labor services) is responsible for the remittance of various payroll taxes to the government, and thus may choose to evade these taxes. However, this would make the model more complex without changing its basic results.
} 
all penalties. Assume further that the probability of being audited is increasing with underground labor income, $y_{u}=w_{u} h_{u}$, where $w_{u}$ and $h_{u}$ are respectively the individual's wage rate and his hours worked in the underground sector. This probability is also decreasing with the level of resources, $R$, devoted by the individual to hide his underground working activities and a function of a vector $z_{1}$ of exogenous variables (which includes the penalty rate):

$$
p=\max \left[0, p^{*}\left(y_{u}, R, z_{1}\right)\right],
$$

with $p^{*}(\cdot)<1, \partial p^{*} / \partial y_{u}>0, \partial p^{*} / \partial R<0, p^{*}\left(0,0, z_{1}\right)=0$ and with $p^{*}\left(y_{u}, R, z_{1}\right)$ strictly quasi-convex in $\left(y_{u}, R\right)$.

To simplify, we also assume that the penalty rate is sufficiently high so that it is optimal for an underground worker to devote the minimum amount of resources required to make the probability of being audited equal to zero. Under this assumption, the problem becomes one with perfect certainty. ${ }^{10}$ Letting $p^{*}\left(y_{u}, R, z_{1}\right)=0$ and solving for $R$ yields:

$$
R=R\left(y_{u}, z_{1}\right)
$$

with $R\left(0, z_{1}\right)=0, \partial R / \partial y_{u}>0$ and $\partial^{2} R / \partial y_{u}{ }^{2}>0$. Equation (2) indicates that the minimum amount of resources needed by the individual to be sure he will not be caught, is increasing at an increasing rate with his labor income in the underground sector, $y_{u}$, given the level of exogenous variables, $z_{1}$.

The marginal (and average) cost of access to underground commodities, $c$, is a decreasing function of hours worked in the underground sector, $h_{u}$, and a function of a vector of exogenous variables, $z_{2}$ :

$$
c=c\left(h_{u}, z_{2}\right),
$$

with $\partial c / \partial h_{u}<0$.

Using equations (2) and (3) and the definition of underground labor income, the individual's budget constraint therefore is:

$$
P_{r} C_{r}+\left(P_{u}+c\left(h_{u}, z_{2}\right)\right) C_{u}=w_{u} h_{u}+\left(w_{r} h_{r}+y\right)(1-t)-R\left(w_{u} h_{u}, z_{1}\right),
$$

\footnotetext{
${ }^{10}$ This concealment cost approach is thus consistent with the standard tax evasion model (Cowell, 1991). The assumption that tax evasion entails real or psychic costs while being foolproof has been used recently by authors dissatisfied with the lack of predictive power of models based on risk aversion [e.g., see Usher (1986), Kesselman (1989), Fortin, Marceau and Savard (1997)]. Note that the model does not predict that no underground worker will be controlled since $p$ refers to the subjective probability of being controlled, which may differ from the true probability.
} 
where subscripts $r$ and $u$ stand for the regular and the underground sectors, respectively; $P_{i}$ is the price of goods or services in sector $i, C_{i}$ is the consumption of goods and services in sector $i, w_{i}$ is the wage rate in sector $i$ and $h_{i}$ is the hours of work in sector $i$, for $i=u, r ; y$ is the nonwage income and $t$ is the (proportional) income tax rate. The individual is assumed to have no influence on the prices of commodities in each sector, $P_{r}$ and $P_{u}$, where $P^{r}$ is gross of the sales taxes. However, since the cost of access to underground commodities depends on a choice variable, the price of irregular commodities gross of the marginal access cost to the irregular sector, is an endogenous variable. ${ }^{11}$

Preferences over all goods are represented by the utility function $U\left(C_{r}, C_{u}, h_{r}, h_{u} ; z_{3}\right)$, where $z_{3}$ is a vector of demographic variables influencing preferences. The individual is thus assumed to solve the following program:

$$
\max _{\left\{C_{r}, C_{u}, h_{r}, h_{r}\right\}} U\left(C_{r}, C_{u}, h_{r}, h_{u} ; z_{3}\right),
$$

subject to equation (4) and to the non-negativity constraints on the choice variables. ${ }^{12}$

The unconditional demand functions for regular and underground commodities, and the labor supply for both markets can be derived from the first-order conditions to this program. However, since we want to estimate the relationship between hours of work in each sector and the demand for undeclared goods and services, it is more appropriate, following Browning and Meghir (1991), to adopt the conditional demand approach. For this matter, we first derive the demand function for undeclared commodities conditional on the hours of work in each sector (the conditioning goods) and on total expenditures on both declared and undeclared commodities. Interestingly, the functional form for this demand equation does not depend upon whether the hours of work are zero or positive ${ }^{13}$. Moreover, it holds even when hours of work are rationed in one or both sectors. Setting hours of work at levels $h_{u}$ and $h_{r}$, the program to be solved is now:

\footnotetext{
${ }^{11}$ It would be easy to generalize the model to allow the marginal cost of access to underground commodities to depend on the level of consumption of underground commodities. However, this would make comparative static results more difficult to interpret.

${ }^{12}$ Barter of goods and services produced informally is not modeled since it represents less than $6 \%$ of the size of underground economy in our sample.

${ }^{13} \mathrm{On}$ the contrary, it is clear, from Kuhn-Tucker conditions, that the functional form for the unconditional demand for irregular commodities will vary depending upon whether the individual works or not in each market, which makes the estimation of the model much more complex to perform [e.g., see Wales and Woodland (1983)].
} 


$$
\max _{\left\{C_{r}, C_{u}\right\}} U\left(C_{r}, C_{u} ; h_{r}, h_{u}, z_{3}\right),
$$

subject to

$$
P_{r} C_{r}+\left(P_{u}+c\left(h_{u}, z_{2}\right)\right) C_{u}=\bar{m}
$$

where $\bar{m}$ is the level of total expenditures on commodities, as given by the right-hand side of equation (4), ${ }^{14}$ and subject to the non-negativity constraints on $C_{r}$ and $C_{u}$. The first-order conditions for an interior solution to this program yield the conditional demand for undeclared goods and services: $:^{15}$

$$
C_{u}=\bar{C}_{u}\left(P_{r}, P_{u}+c\left(h_{u}, z_{2}\right), \bar{m}, h_{u}, h_{r}, z_{3}\right) .
$$

Differentiating equation (7) with respect to $h_{u}$ and using the definition of $\bar{m}$, it is possible to decompose the effect of an increase in hours of work in the irregular sector on the demand for irregular commodities into three separate effects: a network effect, an income effect and a non-separability effect. They correspond to the three terms on the right-hand side of the following equation:

$\partial C_{u} / \partial h_{u}=\partial \bar{C}_{u} / \partial \tilde{P}_{u} \partial c / \partial h_{u}+\partial \bar{C}_{u} / \partial \bar{m} w_{u}\left(1-\partial R / \partial y_{u}\right)+\partial \bar{C}_{u} / \partial h_{u}$,

where $\tilde{P}_{u}=P_{u}+c\left(h_{u}, z_{2}\right)$. The first term, corresponding to the network effect, will be positive as long as the output from the irregular sector is not a Giffen good. The second term, which reflects an income effect, will also be positive as long as the latter output is not an inferior good and that $w_{u}\left(1-\partial R / \partial y_{u}\right)>0$. This latter expression corresponds to the underground wage rate net of the marginal cost of hours of work in the underground sector (in terms of resources needed to hide underground income). The non-separability effect, as expressed by the third term, requires more explanation. Leaving aside the network and income effects, one can show that the hours of work in the irregular sector will have no effect on the demand for irregular commodities, as long as labor supplies (i.e., the conditioning goods) and commodity demands (i.e., the

\footnotetext{
${ }^{14}$ In our static model which ignores saving, total expenditures on regular and irregular commodities are equal to the net disposable income. Note also that the net disposable income may incorporate a non-linear tax-transfer system, since our analysis is conditional on $\bar{m}$.

${ }^{15}$ One can also derive this conditional demand function from a dual approach based on the conditional cost function [e.g., see Browning (1983)].
} 
conditioned goods) are weakly separable. ${ }^{16}$ This will be the case if the utility function can be written in the form $F\left(u\left(C_{r}, C_{u}, z_{3}\right), h_{r}, h_{u}, z_{3}\right)$. Therefore, under weak separability the third term on the right-hand side of equation (8) will be equal to zero. A positive (negative) term indicates that hours of work in the irregular sector and consumption in the irregular sector are complements (substitutes). ${ }^{17}$

A similar analysis can be used to study the impact of hours of work in the regular sector on the demand for irregular commodities. Differentiating equation (7) with respect to $h_{r}$ and using the definition of $\bar{m}$, one gets:

$$
\partial C_{u} / \partial h_{r}=\partial \bar{C}_{u} / \partial \bar{m} w_{r}(1-t)+\partial \bar{C}_{u} / \partial h_{r} .
$$

As shown in equation (9), there are only two effects when a change in hours of work in the regular sector occurs: an income effect and a non-separability effect. This result stems for the fact that the network effect is ruled out in the case of a change in $h_{r}$ since it is assumed that sellers of goods and services in the regular sector can easily be found.

Ideally, one would like to estimate the conditional demand for irregular commodities, as given by equation (7). However, it cannot be estimated since we have no information on the marginal cost of access to irregular commodities, $c$. Similarly, no information is available on the cost of hiding underground working activities, $R$. Therefore, we must estimate a quasi-reduced form of the conditional demand function, as obtained from equation (7) and with the use of the gross disposable income, $m$, (with $\left.m=\bar{m}+R\left(y_{u}, z_{1}\right)\right)$ :

$$
C_{u}=C_{u}\left(h_{u}, h_{r}, m, z\right),
$$

where $z$ is the vector of exogenous variables $\left(z=\left(z_{1}, z_{2}, z_{3}\right)\right)$ and where the prices $P_{r}$ and $P_{u}$ have been normalized to one.

The objective of our econometric analysis is to estimate equation (10), where $C_{u}$ can be interpreted as total expenditures in the irregular sector (since $P_{u}=1$ ). Note that in this equation, the impact of $h_{u}$ on the demand for irregular commodities takes into account the network effect, the non-separability effect and a "resource" effect, that is, the income effect associated with a change in the resources used to hide irregular activities. Therefore, it will not be possible to estimate these three effects separately. Moreover, as long as the size of the non-separability effects

\footnotetext{
${ }^{16}$ This result is an application of a theorem by Pollak (1971).

${ }^{17}$ The relationship between this definition of complements (substitutes) and the standard one based on the sign of cross compensated effects is provided in Neary and Roberts (1980).
} 
associated with a change in $h_{u}$ and in $h_{r}$ are similar and that the resource effect is small, the impact of a change in $h_{u}$ will exceed that of a change in $h_{r}$. This result, which is due to the network effect, will be tested in the econometric section.

\section{Econometric Issues}

It is natural to estimate the conditional demand for irregular commodities using an instrumental variable (IV) approach, given that the hours of work in each sector and the disposable income are potentially endogenous [see Browning and Meghir, (1991)]. Moreover using an IV approach does not require us to specify the labor supply equations. However, one must take into account the fact the dependent variable, $C_{u}$, is censored at zero. Consider the following latent variable model for individual $i$ :

$$
C_{u i}^{*}=\gamma^{\prime} x_{i}+\mu_{i},
$$

where $\gamma$ is a vector of parameters to be estimated, $x_{i}$ is the vector of explanatory variables, some of which are potentially endogenous, $\mu_{i}$ is an error term $\sim N\left(0, \sigma^{2}\right)$, and $C_{u i}^{*}$ is the latent variable to be explained. While the value of $C_{u i}^{*}$ is not observable, an indicator function $C_{u i}$ is observed and is related to $C_{u i}^{*}$ in the following manner:

$$
C_{u i}= \begin{cases}C_{u i}^{*} & \text { if } C_{u i}^{*}>0 \\ 0 & \text { otherwise }\end{cases}
$$

Estimating equation (11) using GMM is motivated by the fact that the standard tobit model can be estimated consistently using a Nonlinear Least Squares (NLLS) method. Two general classes of estimators are available for this purpose: estimators based on either the expectation function (EF) of $C_{u i}$ or the expectation function of $C_{u i}$ conditional on $C_{u i}^{*}>0$ (CEF). Moreover, as shown by Stapleton and Young (1984), the $\mathrm{EF}$ and the CEF expectation estimators are robust to measurement error on the positive value of the dependent variable, which is not the case for the standard maximum likelihood (ML) estimator of the tobit model. ${ }^{18}$

\footnotetext{
${ }^{18}$ The reason why the standard $\mathrm{ML}$ estimator is not consistent in the presence of measurement error is that the estimator of the auxiliary parameter, the variance of the error term, is based in part on the variance of the dependent variable. Since measurement error increases this variance, its estimator is biased upward and this bias is transmitted to the coefficient estimators. On the contrary, measurement error does not affect the consistency of EF or CEF estimators since no parameters from the (unspecified) distribution of the measurement appear in the EF or in the CEF.
} 
The EF of $C_{u i}$, given $x_{i}$, is (see Amemiya 1985, p. 368):

$$
E\left(C_{u i} \mid x_{i}\right)=\Phi(\cdot) \gamma^{\prime} x_{i}+\sigma \phi(\cdot) \equiv F\left(x_{i}, \theta\right),
$$

where $\phi(\cdot)$ and $\Phi(\cdot)$ are respectively the density and the cumulative functions of the standard normal distribution, evaluated at $\gamma^{\prime} x_{i} / \sigma$, and where $\theta=\left(\gamma^{\prime}, \sigma\right)^{\prime}$.

On the other hand, the CEF of $C_{u i}$, given $x_{i}$, is given by (see Amemiya 1985, p. 367):

$$
E\left(C_{u i} \mid C_{u i}>0, x_{i}\right)=\gamma^{\prime} x_{i}+\sigma \frac{\phi(\cdot)}{\Phi(\cdot)} \equiv F^{c}\left(x_{i}, \theta\right),
$$

where $\phi(\cdot) / \Phi(\cdot)$ is Mills' ratio. From equations (12) and (13), both the $\mathrm{EF}$ and the CEF of $C_{u i}$ are nonlinear functions of $\gamma$ and $\sigma$. Naturally, NLLS estimates of these equations are inappropriate if any of the $x_{i}$ are endogenous. We therefore rely on GMM estimates with White's correction for heteroskedasticity. More specifically, let us focus on the model based on the EF of the dependent variable. It is specified as:

$$
C_{u i}=\Phi(\cdot) \gamma^{\prime} x_{i}+\sigma \phi(\cdot)+\epsilon_{i}
$$

where, by equation (12), $E\left(\epsilon_{i} \mid x_{i}\right)=0$. Now, define $F(x, \theta)$ as the mean function of the vector of observations on consumption, $C_{u}$, where $x$ is the matrix of observations on explanatory variables. Given a set of instruments $W$ satisfying the moment conditions $E\left[C_{u i}-F\left(x_{i}, \theta\right)\right] W_{i}=$ 0 , the GMM estimator for $\theta$, in the case where there are more moment conditions than there are parameters to estimate, is chosen to minimize:

$$
\left[C_{u}-F(x, \theta)\right]^{\prime} W\left(W^{\prime} \Omega W\right)^{-1} W^{\prime}\left[C_{u}-F(x, \theta)\right],
$$

where $\left(W^{\prime} \Omega W\right)$ is the covariance matrix of $W^{\prime}\left[C_{u}-F(x, \theta)\right]$. The diagonal matrix $\Omega$ is not observable. However, it can be approximated by a heteroskedasticity-consistent covariance matrix estimator (HCCME) $\hat{\Omega}$, of which the $i^{t h}$ diagonal element is given by $\hat{\epsilon}_{i}^{2}=\left[C_{u i}-F\left(x_{i}, \hat{\theta}\right)\right]^{2}$, where $\hat{\theta}$ is obtained in a first step using a nonlinear instrumental estimation. The latter consists of minimizing equation (15) with $\Omega$ being replaced by the identity matrix [see White (1980)].

While the estimator of $\theta$ obtained using the HCCME $\hat{\Omega}$ has good asymptotic properties, it is possible to modify it so that it has better finite-sample properties. MacKinnon and White (1985) concluded that a different HCCME (denoted $\tilde{\Omega}$ ) generally seems to perform better in

Of course, these estimators are asymptotically less efficient than a correctly specified ML estimator, but the latter requires the specification of the measurement error. 
Monte Carlo experiments. The $i^{\text {th }}$ diagonal element of this HCCME is given by $\hat{\epsilon}_{i}{ }^{2} /\left(1-\hat{h_{i}}\right)^{2}$, where $\hat{h}_{i}=f_{i}\left(f^{\prime} f\right)^{-1} f_{i}{ }^{\prime}$ is the $i^{t h}$ diagonal of the "hat" matrix $\hat{P}_{f}$ that projects orthogonally onto the space spanned by the columns of $f$, with $f=\partial F(x, \theta) /\left.\partial \theta\right|_{\theta=\hat{\theta}}$.

Following an iteration process suggested by Mackinnon and Davidson (1993), equation (15) is first minimized starting with $\Omega=I$; next we compute $\tilde{\Omega}$ and minimize (15) again. Upon convergence, we compute $\tilde{\Omega}$ with the new set of parameter estimates and minimize again (15) until both $\tilde{\Omega}$ and $\tilde{\theta}$ converge to stable values. The covariance matrix of $\tilde{\theta}$ is then estimated as:

$$
(\tilde{f})^{\prime} W\left(W^{\prime} \tilde{\Omega} W\right)^{-1} W^{\prime}(\tilde{f}) .
$$

where $\tilde{f}=\partial F(x, \theta) /\left.\partial \theta\right|_{\theta=\tilde{\theta}}$.

A similar approach is used to estimate the model based on the CEF of the dependent variable. In this case, the function $F^{c}(x, \theta)$, as defined in equation (13), is substituted for $F(x, \theta)$ in equation (15).

\section{Empirical Results}

Since there are three potentially endogenous variables in the conditional demand equation (10), we need at least three identifying restrictions. This raises the issue of the choice of instruments. Unfortunately, economic theory does not have much to say about this. Browning and Meghir (1991), in their analysis of a household demand system conditional upon hours of work and labor participation of the husband and wife, use, among others, asset income, education, male age and nonlinear combinations of these variables as instruments. They argue that the exclusion of asset income is in line with a two-stage budgeting approach while education is a proxy for the wage rate (not available for individuals who do not work). They also provide overidentifying tests to evaluate the validity of their exclusion restrictions. Our strategy closely follows their approach. The complete list of instruments we use is nonlabor income $(N L I N C)^{19}$, nonlabor income squared, dummies for primary education (PRIMEDU), for college (high school) education (COLEDU) and for university education (UNIVEDU), experience (EXP), experience squared, experience cubed, age squared, age cubed, total number of children (NCHILD), presence of preschool children in the household ( $C H I L D 6)$, dummies for single-person household (SINGLE), for oneparent household (ONEPAR) and for other household situation (room-

\footnotetext{
${ }^{19}$ This variable was computed as the sum of interest and dividend income, net capital gains, property income, alimony, and retirement income (no earnings test).
} 
mate, grandparent, friend, etc) $(O T H D)^{20}$, a dummy if the individual reports that he would have preferred to work more annual hours in the regular market at his ongoing wage rate $(R A T I O N)$, and a dummy if the individual reports that his family and social circle would not disapprove if they found out that he worked in an irregular job $(R E A C) .^{21}$

The variables included in the vector $z$ in equation (10) are also used as instruments. After considerable experimentation, the variables DSEX (female=1), AGE, regional dummies for the region of Montreal (MONTREAL) and for the region of Bas-St-Laurent (BAS ST-LAUR) were included in $z$.

Table 2 provides descriptive statistics for the variables used in the regressions. As compared with the average consumer in the full sample, consumers of irregular goods and services report, on average, a higher disposable income and work more hours in both labor sectors. In particular, their hours of work in the irregular labor sector are almost four times those observed for the average consumer in the full sample. The proportion of women who purchase irregular goods and services is lower than that of men. Indeed, while there are $56.1 \%$ of women in the full sample, there are only $50 \%$ of women in the sample of individuals who purchase irregular commodities. Furthermore, the proportion of underground consumers is somewhat lower in the region of Montreal and in the region of Bas St-Laurent than in the region of Quebec. Finally, 61.1\% of respondents in the full sample think that their family and social circle would not disapprove if they found out that he/she had an irregular job (see variable $R E A C$ ).

In Table 3, we present the parameter estimates of the expenditures on irregular goods and services. The first three columns report results for the full sample. The fourth and fifth columns report results for the sample conditional on positive consumption.

After some experimentation, a specification that is linear in the log of disposable income and in all other variables was used. This specification proved to be very robust to the choice of variables, the scaling of variables and the choice of instruments. Quadratic and interactive terms in $h_{u}$, $h_{r}$ and $\log m$ never turned out to be statistically significant. Other more general specifications were also estimated, including the AIDS specification, but difficulties of convergence were encountered. In fact, given the

\footnotetext{
${ }^{20}$ The residual household category is individual living with parent(s).

${ }^{21} \mathrm{~A}$ natural reaction to the use of this latter instrument is that it is likely to be correlated with the error term of the conditional demand function. Indeed, if an individual's family or social circle tolerates underground work, they are likely to tolerate underground consumption. However, when also introduced directly as an explanatory variable in equation (10), the variable $(R E A C)$ was never significant in any specification.
} 
small number of observations on positive expenditures, we did not have enough variability in the sample to estimate more complex functional forms.

The first column presents the results from a standard tobit model under the assumption that all the independent variables are exogenous. Except for the Montreal region variable, the other variables in this regression are statistically significant (at the $5 \%$ or the $10 \%$ level). In particular, the propensity to consume irregular commodities is lower for women than for men. The parameter estimates associated with hours of work in the regular and the irregular sectors are both positive and significant, with the coefficient of $h_{u}(=1.47)$ much greater than the one associated with $h_{r}(=0.108)$.

The second column provides the NLLS estimates of the EF model. Qualitatively, the signs of all coefficients are similar to those obtained for the tobit (except for the DSEX variable, which is not significant), but the NLLS estimates are larger (in absolute value) than those of the tobit. The coefficients associated with the income variable (in logs) are similar (3.2 vs 4.3). Also, as in the tobit, the coefficient of $h_{u}(=4.64)$ is larger than the coefficient $h_{r}(0.459)$. While the value of these coefficients exceed those of the tobit, their ratio is similar.

The tobit and the NLLS estimates are not consistent if some righthand side variables are endogenous. The GMM estimates of the EF model, which take into account the endogeneity of the hours of work and the income variables, are reported in the third column. Before discussing the results, let us focus on an exogeneity test of these variables. For this matter, we use a standard Hausman test based on a comparison between GMM and NLLS estimators. This is an appropriate test since under the null hypothesis of exogeneity of the independent variables, the NLLS estimator is more efficient asymptotically than the GMM estimator but loses consistency under the alternative hypothesis. On the other hand, the GMM estimator is asymptotically less efficient than the NLLS estimator under the null hypothesis but remains consistent under the alternative hypothesis. The test statistic, provided in Table 4, is 81.83 and is to be compared with the critical value of the $\chi^{2}$ with 9 degrees of freedom at the $5 \%$ level $(=16.92)$. Therefore we easily reject exogeneity. ${ }^{22}$

\footnotetext{
${ }^{22}$ We also performed a Hausman test based on a comparison between GMM and tobit estimators. We also concluded that exogeneity is rejected. Note that the latter test is valid only under the maintained hypothesis of no measurement error on the positive value of the dependent variable, since the tobit model is not robust to this hypothesis.
} 
In Table 4, we also report Hansen's statistic in order to perform a joint test of the validity of our instruments and of our overidentifying restrictions. We conclude that these hypotheses are not rejected at the $5 \%$ level. Also, in the upper part of Table 6, we present a sensitivity analysis of the GMM results for the EF estimator to various choices of instruments: exclusion of the RATION variable, of the NLINC variable and of the EDUCATION dummies; inclusion of the INCAP variable, a dummy variable $=1$ if the individual reports to have been absent from work due to sickness or accident over the year. A glance at the results shows that they are quite robust with respect to the choice of these instruments. Therefore, our analysis focuses on the GMM estimates provided in Table 3.

Each of the GMM estimates of the hours of work variables in the regular and the irregular sectors is statistically significant. Therefore we reject the joint hypothesis of separability and of the absence of both a network effect and a resource effect in the underground sector. We also reject the separability hypothesis in the regular sector. In Table 4, both a Wald test and a Newey-West (1987) test indicate that we reject the hypothesis that the coefficients associated with the hours of work in the regular and irregular sectors are jointly equal to zero. ${ }^{23}$ Moreover, a Wald test rejects the equality of the effects of the hours of work variables. In fact, the coefficient on hours of work in the underground sector $(=$ $2.55)$ is 31 times larger than the coefficient of hours of work in the regular sector $(=0.082)$. This result confirms a much larger effect of labor supply in the underground sector on the level of expenditures on underground commodities. Interestingly, the coefficient of the variable of hours of work in the irregular sector is smaller than the corresponding one based on NLLS. This indicates that part of the observed correlation between this variable and the consumption in the irregular sector is due to the presence of unobserved variables that affect both variables in the same direction. Finally, the coefficient associated with the disposable income is positive and significant at the $5 \%$ level, which implies that consumption in the irregular sector is a normal composite good.

The two last columns provide the estimation results based on the CEF. Nonlinear least squares estimates are presented in the fourth column while GMM estimates are reported in the last column. Based on a

\footnotetext{
${ }^{23}$ The Wald statistic is based on the same formula as the one used in the context of maximum likelihood estimation. The Newey-West test is the counterpart of the likelihood ratio test in the context of GMM estimation. The statistic used to perform the test is equal to the difference in the values of the criterion to be minimized for GMM estimation when the constraints to be tested are imposed and when they are not. It is distributed as a $\chi^{2}$ with the degrees of freedom equal to the number of constraints $(=2)$.
} 
Hausman test with a value of 49.62 (see Table 4), the exogeneity of the explanatory variables is again strongly rejected. Therefore, we concentrate the discussion on the GMM estimator.

As in the case of the GMM results based on the EF, we performed a set of hypothesis tests. Hansen's test (with a test statistic of 8.14) does not reject the validity of the instruments and of the overidentifying restrictions. Moreover, based either on a Wald test (statistic of 14.18) or a Newey-West test (statistic of 6.27), we reject the hypothesis that hours of work in both regular and irregular sectors have no effect on expenditures in the irregular sector. From a Wald test with a statistic of 7.45 , we also reject the hypothesis of the equality of the effects of hours of work in each sector. In short, all these tests based on the CEF estimator confirm those performed using the EF estimator. Sensitivity analysis presented in the lower part of Table 6 also confirms that the estimates are robust to the choice of instruments.

Under the assumptions made in the previous section, both the EF and the CEF estimators obtained from GMM should be consistent even in the presence of measurement errors on uncensored observations of the dependent variable. ${ }^{24}$ However, given that the EF estimator uses more information than the CEF estimator (since the former uses the full sample while the latter uses a truncated sample), one should expect, on intuitive grounds, the EF estimator to be asymptotically more efficient than the CEF estimator. However, Stapleton and Young (1984) were unable to show that this is necessarily the case. ${ }^{25}$ Comparing results from the third and the fifth columns of Table 3, one observes that they are qualitatively similar when the estimates are significant in both regressions. Quantitatively, however, there are some differences worth emphasizing, especially concerning key economic variables. Thus the coefficient on log-income is negative based on the CEF estimator, suggesting that underground consumption is an inferior composite good. However, the coefficient is not statistically significant with a $t$-value of 0.92. The coefficients on the hours of work variables are still positive and significant. Moreover, the coefficient of hours of work in the underground sector is still larger than the one of hours of work in the regular sector and this difference is statistically significant, as suggested by the Wald test reported in Table 4. However, it is considerably smaller than the difference estimated using the EF estimator. Indeed, based on the

\footnotetext{
${ }^{24}$ One must also assume that the expectation of the measurement error is zero and that its higher moments are bounded [see Stapleton and Young (1984)].

${ }^{25}$ One reason is that the variance of the dependent variable may be larger in the full sample than in the truncated sample, for certain values of the coefficients and of the independent variables.
} 
CEF estimator, the effect of hours of work in the irregular sector is only 3.1 times the one of hours of work in the regular sector. Despite some quantitative differences, these results confirm that labor supply in the underground sector has a dominant positive effect on the consumption of irregular commodities. This holds even when one takes into account the endogeneity of labor supply variables, due for example to a positive correlation between unobservable tastes for working and for consuming in the underground sector.

One could speculate that the difference between the EF and the CEF estimators is partly due to the fact that the latent models which determine the probability of consuming irregular commodities and the level of positive consumption are not the same. A natural explanation is the existence of fixed participating costs of consuming irregular commodities (e.g., fixed costs of access to the underground sector). Indeed, these costs will negatively affect the probability of consuming irregular commodities but will have a positive influence on the level of consumption, as long as it is a normal good. ${ }^{26}$ The existence of substantial participating costs, however, should also imply a minimum level of expenditures on underground commodities by the consumers of these commodities. This implication is not supported by the data, as shown in Figure 1 which plots the frequency distribution of expenditures on underground goods and services in the restricted sample. Indeed, one does not observe an important discontinuity of this distribution at a level corresponding to no expenditures.

What are the effects of changes in the level of disposable income and of hours of work in each sector on the expected level of expenditures in the underground sector? Table 5 reports results from GMM estimates of Table 3 applied both to the full sample and to the restricted sample. All the results are calculated at the mean of the explanatory variables for the full sample.

At the $5 \%$ level of significance, the GMM estimates using the full sample show that a $1 \%$ increase in the disposable income yields an increase of $\$ 1.06$ in the expected level of irregular consumption. The corresponding elasticity of irregular consumption with respect to disposable income is 0.55 , which implies that irregular consumption is a necessary good. Based on the GMM estimates using the restricted sample, the effect of disposable income on irregular consumption is negative but not significant. Furthermore, the effect of an annual increase of 100 hours of work in the regular sector is to raise the expected irregular consump-

\footnotetext{
${ }^{26}$ See Cogan (1981) for a classical analysis of the effect of fixed costs on individual choices applied to labor supply.
} 
tion by $\$ 8.20$. For a similar increase in hours in the irregular sector, the increase in irregular consumption reaches $\$ 254.80$ (estimates based on full sample). When using the estimates based on the restricted sample, the effect rises to $\$ 37.10$ for an annual increase of 100 hours in the regular sector while it declines to $\$ 114.90$ for hours of work in the irregular sector. While the difference between these two effects gets smaller (in absolute value), working additional hours in the irregular rather than in the regular sector still produces a much higher impact on irregular consumption.

\section{Policy Simulations}

Our results raise important policy issues. Indeed, government policies which affect the supply of irregular activities will also influence the demand for these activities. If the latter effect is neglected, one is likely to underestimate the impact of the policy on the size of the underground economy. To illustrate, assume that the government succeeds in reducing the level of hours worked in the irregular sector by $1 \%$ at given wages and prices level. ${ }^{27}$ Differentiating the log of eq.(10) with respect to $h_{u}$ and using the definition of the gross disposable income, $m$, the effect of this policy on the irregular expenditures of the representative underground worker, is given by:

$$
d \log C_{u}=\left[\eta_{C_{u}, h_{u}}+\eta_{C_{u}, m}\left(w_{u} h_{u} / m\right)\right] d \log h_{u},
$$

where $\eta_{i, j}$ is the elasticity of $i$ with respect to $j$.

The representative underground worker works 339 hours per year in the underground sector; his irregular expenditures are $\$ 817$, his gross disposable income is $\$ 10739$ and his underground labor income is $\$ 2$ 732. Using this information and the coefficients of table 5, one finds that a $1 \%$ decrease in his irregular hours of work induces him to reduce his irregular expenditures by a percentage varying between $0.53 \%$ and $1.09 \%$, depending on whether one uses the GMM coefficients based on the restricted sample or the full sample. One should note that these figures depend essentially on the network and the non-separability effects, since the income effect is very small. Indeed, if one assumes no income effect, these figures will be very close to those already obtained, varying between $0.476 \%$ and $1.06 \% .^{28}$

\footnotetext{
${ }^{27}$ The government could reach this objective by adopting more severe enforcement parameters which induces the underground workers to reduce their labor supply in the underground economy.

${ }^{28}$ In the analysis, one does not take into account the impact of the adoption of a more severe enforcement system on the level of resources used by the worker to hide
} 
Since the underground expenditures made by the underground workers represent $34.9 \%$ of total underground expenditures in the sample, the impact of the policy on total underground expenditures will vary between $0.185 \%(=0.0053 \times 0.349)$ and $0.38 \%(=0.0109 \times 0.349)$ or $0.166 \%$ and $0.37 \%$, neglecting the income effect. To assess the importance of this impact on the reduction in the size of the underground economy, we need a model of the determinants of output in the underground sector. Consider, for simplicity, the following short run partial equilibrium model of demand and supply for underground output:

$$
\begin{aligned}
Q_{u} & =Q^{d}\left(H_{u}, P_{u}\right), \\
H_{u} & =\bar{H}_{u} h^{s}\left(w_{u}\right), \\
Q_{u} & =\bar{K}_{u}^{1-a} H_{u}{ }^{a}, \quad \text { with } 0<a<1, \\
H_{u} & =\bar{K}_{u}\left(\frac{w_{u}}{a P_{u}}\right)^{1 / a-1},
\end{aligned}
$$

where $Q_{u}$ and $H_{u}$ are respectively the market quantity of underground output and of underground hours of work and $\bar{K}_{u}$ is the stock of capital, assumed fixed in the short run. The regular output is the numeraire $\left(P_{r}=1\right)$. Firms are assumed identical and their number is fixed. Consumers are also identical and receive a wage rate, $w_{u}$. Income effects are ignored for simplicity. Equation (18) is the market demand function for underground output conditional on hours of work, with $Q_{H_{u}}^{d}>0$ and $Q_{P_{u}}^{d}<0$. Equation (19) is the underground labor supply, with $h_{w_{u}}^{s}>0$. The variable $\bar{H}_{u}$ is the shift parameter, which is under the government control. For simplicity, it is assumed that the relative price of underground output, $P_{u}$, does not affect the labor supply. Assuming a Cobb-Douglas technology with constant returns to scale, equation (20) gives the market production function. Equation (21) is the profitmaximizing market demand for hours of work consistent with the CobbDouglas technology. There are four endogenous variables in this model: $Q_{u}, H_{u}, P_{u}$ and $w_{u}$.

Now let us study the impact of a change in the supply of underground hours of work on the size of the underground economy. Differentiating the system with respect to the log of the shift parameter yields, after some manipulations:

his irregular income. Moreover, we assume that hours of work in the regular sector are not affected by the policy. Under the assumption that the individual adjusts his hours of work in the regular sector so as to leave unchanged his total hours of work, the impact on irregular expenditures will be smaller but still important, varying between $0.282 \%$ and $1.02 \%$ (assuming no income effect). 


$$
\partial \log \left(P_{u} Q_{u}\right) / \partial \log \bar{H}_{u}=\frac{a\left(\eta^{d}-1\right)+\bar{\eta}}{\eta^{d}\left(1+\eta^{s}(1-a)\right)+\eta^{s}(a-\bar{\eta})},
$$

where $\eta^{d}$ and $\eta^{s}$ are respectively the absolute value of the price elasticity of demand and supply and $\bar{\eta}$ is the elasticity of $Q^{d}$ with respect to $H_{u}$. The model is stable when the denominator of equation (22) is positive. This will be the case if the induced effect of hours of work on the demand for underground output is not too strong, that is, if $\bar{\eta}<a$. This inequality is assumed to hold in the analysis.

Equation (22) shows that if $\eta^{d}=1$ and $\bar{\eta}=0$, there is no impact on the size of the underground sector associated with a shift of the supply curve. The reason is that, in this case, the percentage change in the price of underground output is equal to minus the percentage change in the equilibrium underground output. If the demand elasticity is smaller than $1-\bar{\eta} / a$, the numerator of equation (22) will be negative. In this case, the impact of a government policy which reduces by $1 \%$ the supply of irregular hours of work will actually increase the size of the underground sector. A price inelastic demand is unlikely, however, given the possibility of substituting regular for irregular commodities. Therefore, we will assume in the sequel that $\eta^{d}>1>1-\bar{\eta} / a$.

By ignoring the induced demand effect of a government policy which affects the supply of underground output, one will underestimate its total effect by the following percentage:

$$
B=\frac{\left(1+\eta^{s}\right) \bar{\eta} \eta^{d}}{\left[\eta^{d}\left(1+\eta^{s}(1-a)\right)+\eta^{s}(a-\bar{\eta})\right]\left[a\left(\eta^{d}-1\right)+\bar{\eta}\right]}>0 .
$$

From equation (23), one can show that the underestimation bias, $B$, is positively related to the price elasticity of supply, $\eta^{s}$, and the elasticity of $Q^{d}$ with respect to $Q^{s}, \bar{\eta}$. It also decreases with an increase in the price elasticity of demand, $\eta^{d}$.

In Table 7, we report the underestimation bias associated with neglecting the direct impact on the demand for underground output of a government policy which reduces by $1 \%$ the supply of irregular hours of work. The simulations are conducted for different values of the elasticities associated with equation (23). The elasticity of output with respect to hours of work, $a$, which reflects the share of labor income in the underground economy, is set at 0.75 . Two values for $\bar{\eta}$, corresponding to those discussed above, are considered, 0.166 and 0.370 .

The biases are important. Even with a low elasticity of supply, $\eta^{s} \leq$ .5 , and a large price elasticity of demand, $3 \geq \eta^{d} \geq 2$, the bias still 
ranges from $10 \%$ to $37.7 \%$. As the elasticity of output with respect to hours of work gets higher, the bias decreases but not very much. Thus when $a \rightarrow 1$, it ranges from $7.66 \%$ to $32.4 \%$. Finally, the bias reaches $100 \%$ when $\eta^{d}=1$ or when $a \rightarrow 0$.

These results show that the induced demand effect significantly raises the efficiency of a successful intervention by the government authorities of reducing the underground labor supply. Similarly, a decrease in the marginal income tax rates that reduces irregular labor activities is likely to have a significant negative impact on the demand for underground commodities.

\section{Conclusion}

In this paper, we have investigated the relation between work in the irregular sector and the level of irregular expenditures. At the theoretical level, we have shown that this effect can be decomposed into a network effect, a non-separability effect and an income effect. The network effect is due to the fact that an underground worker is likely to benefit from a reduction in information costs as a buyer of irregular commodities. We have thus estimated a model of irregular expenditures including hours of work in both the regular and the irregular sectors as explanatory variables. Endogeneity of these variables as well as selectivity and measurement error on the dependent variable are controlled through GMM techniques. The estimations use micro data from a randomized survey carried out in three regions of the Province of Quebec during 1993. Our results clearly show that, ceteris paribus, individuals who work in the underground economy are more likely to buy goods and services in the underground sector. Moreover, the network and the non-separability effects are much stronger than the standard income effect. We have also found a positive but much weaker relation between work in the regular sector and expenditures on irregular goods. These results have a number of implications both theoretically and for policy.

First, our results show that general equilibrium analysis of the underground economy must take into account the interactions between the demand and the supply sides due to the presence of network and nonseparability effects. To our knowledge, all existing general equilibrium models impose separability between irregular labor supply and consumption and ignore network effects.

The results also have implications both for tax policy and for the system of enforcement. In particular, our empirical findings show that, in the presence of a network effect, the impact of changes in enforce- 
ment parameters (e.g., penalties on tax evasion, expenditures to detect irregular activities) which reduce irregular hours of work are likely to be much stronger on the size of underground economy. The basic reason is that the network effect tends to generate a positive correlation between changes in demand and changes in supply on the underground markets. Thus if individuals who are caught working in the underground economy not only reduce their labor supply in this sector but also sharply decrease their expenditures of irregular commodities, the efficiency of the enforcement policy is likely to be greatly enhanced. Ignoring the latter effect induces significant underestimating biases in the assessment of the impact of the policy on the size of the underground economy. 


\section{References}

[1] Amemiya, T. (1985), Avanced Econometrics, Cambridge, Mass.: Harvard University Press.

[2] Andersen, P. (1977), "Tax Evasion and Labor Supply", Scandinavian Journal of Economics, 79, 375-83.

[3] Browning, M. (1983), "Necessary and Sufficient Conditions for Conditional Cost Functions", Econometrica, 51, 851-856.

[4] Browning, M. and C. Meghir (1991), "The Effects of Male and Female Labor Supply on Commodity Demands", Econometrica,, 599, $925-51$.

[5] Browning, M., F. Bourguignon, P.A. Chiappori and V. Lechene (1994), "Income and Outcomes: A Structural Model of Intrahousehold Allocation", Journal of Political Economy, 102, 1067-97.

[6] Cogan, J. (1981), "Fixed Costs and Labor Supply", Econometrica, $49,945-964$.

[7] Cowell, F. A. (1985), "Tax Evasion with Labor Income”, Journal of Public Economics, 26, 19-35.

[8] Cowell, F.A. (1991), "Tax Sheltering and the Cost of Evasion" in Taxation, Private Information and Capital, P.J. Sinclair and M.D. Slater eds., Oxford: Oxford University Press.

[9] Cowell, F. A. (1990), Cheating the Government, Cambridge Mass.: MIT Press.

[10] Gronau, R. (1977), "Leisure, Home Production, and Work - The Theory of Allocation of Time Revisited", Journal of Political Economy, 86, 1099-1123.

[11] Fortin, B., G. Garneau, G. Lacroix, T. Lemieux and C. Montmarquette (1996), L'économie souterraine au Québec: Mythes et réalités, Sainte-Foy: Les Presses de l'Université Laval.

[12] Fortin, B., N. Marceau and L. Savard (1997), "Tax Evasion, Wage Control and the Informal Sector", Journal of Public Economics, forthcoming.

[13] Kesselman, J. (1989), "Income Tax Evasion: An Intersectoral Analysis", Journal of Public Economics, 38, 137-82. 
[14] Lacroix, G. and B. Fortin (1992), "Utility-Based Estimation of Labour Supply Function in the Regular and Irregular Sectors", Economic Journal, 102, 1407-22.

[15] Lemieux, T., B. Fortin, and P. Fréchette (1994), "The Effect of Taxes on Labor Supply in the Underground Economy ", American Economic Review, 84, 231-254.

[16] MacKinnon, J. and H. White (1985), "Some Heteroscedasticity Consistent Covariance Matrix Estimators with Improved Finite Sample Properties", Journal of Econometrics, 19, 305-25.

[17] Neary, J.P. and K.W.S. Roberts, "The Theory of Household Behaviour under Rationing" European Economic Review, 13, 25-42.

[18] Newey, W. and K. West (1987), "Hypothesis Testing with Efficient Method of Moments Estimation", International Economic Review, $28,777-87$.

[19] Pollak, R. A. (1971), "Conditional Demand Functions and Consumption Theory", Quarterly Journal of Economics, 37, 423-33.

[20] Pestieau, P. (1985), "Belgium's Irregular Economy", in W. Gaertner and A. Wenig, eds., The Economics of the Shadow Economy, New York: Springler-Verlag.

[21] Sandmo, A. (1981), "Income Tax Evasion, Labor Supply and the Equity-Efficiency Trade-Off", Journal of Public Economics, 16, 26588.

[22] Stapleton D.C., and D. J. Young (1984), "Censored Normal Regression with Measurement Error on the Dependent Variable", Econometrica, 52, 738-60.

[23] Usher, D. (1986), "Tax Evasion and the Marginal Cost of Public Funds", Economic Inquiry, 24, 563-86.

[24] Wales, T. J. and A. D. Woodland (1983), "Estimation of Consumer Demand Systems with Binding Nonegativity Constraints", Journal of Econometrics, 2, 263-85.

[25] White, H. (1980), "A Heteroscedasticity-Consistent Covariance Matrix Estimator and a Direct Test for Heteroscedasticity", Econometrica, 48, 817-38. 


\section{Table 1}

Descriptive Statistics on Expenditures on Irregular Goods and Services

\begin{tabular}{|c|c|c|c|c|}
\hline & \multicolumn{2}{|c|}{$\begin{array}{l}\text { Full sample } \\
\quad\left(C_{u} \geq 0\right)\end{array}$} & \multicolumn{2}{|c|}{$\begin{array}{c}\text { Restricted sample } \\
\left(C_{u}>0\right)\end{array}$} \\
\hline & Number & Expenditures* & Number & Expenditures* \\
\hline \multicolumn{5}{|c|}{ Hours of Work, Regular sector } \\
\hline None: $h_{r}=0$ & 577 & $\begin{array}{c}162 \\
(1369)\end{array}$ & 62 & $\begin{array}{c}1507 \\
(3955)\end{array}$ \\
\hline Positive: $h_{r}>0$ & 992 & $\begin{array}{c}209 \\
(878)\end{array}$ & 174 & $\begin{array}{c}1196 \\
(1796)\end{array}$ \\
\hline \multicolumn{5}{|c|}{ Hours of Work, Underground sector } \\
\hline None: $h_{u}=0$ & 1440 & $\begin{array}{c}136 \\
(704)\end{array}$ & 183 & $\begin{array}{l}1071 \\
(1705)\end{array}$ \\
\hline Positive: $h_{u}>0$ & 129 & $\begin{array}{c}817 \\
(2899)\end{array}$ & 53 & $\begin{array}{c}1990 \\
(4280)\end{array}$ \\
\hline All observations & 1569 & $\begin{array}{c}192 \\
(1084)\end{array}$ & 236 & $\begin{array}{c}1277 \\
(2540)\end{array}$ \\
\hline
\end{tabular}

Standard errors are in parentheses.

*1993 Canadian dollars. 


\section{Table 2}

\section{Descriptive Statistics on Independent and Instrumental Variables}

\begin{tabular}{|c|c|c|c|}
\hline \multirow[t]{2}{*}{ Variable } & \multirow[t]{2}{*}{ Definition } & \multicolumn{2}{|c|}{ Descriptive Statistics } \\
\hline & & $\begin{array}{c}\text { Full } \\
\text { Sample } \\
\left(C_{u} \geq 0\right) \\
\end{array}$ & $\begin{array}{c}\text { Restricted } \\
\text { Sample } \\
\left(C_{u}>0\right) \\
\end{array}$ \\
\hline \multicolumn{4}{|c|}{ Endogenous Variables } \\
\hline$m$ & Disposable Income $($ Can $\$) / 1000$ & $\begin{array}{l}13.961 \\
(23.012)\end{array}$ & $\begin{array}{l}18.048 \\
(23.796)\end{array}$ \\
\hline$h_{r}$ & Hours of work, regular sector $/ 100$ & $\begin{array}{c}8.136 \\
(8.558)\end{array}$ & $\begin{array}{l}10.367 \\
(8.977)\end{array}$ \\
\hline$h_{u}$ & Hours of work, irregular sector $/ 100$ & $\begin{array}{c}0.279 \\
(1.602)\end{array}$ & $\begin{array}{c}0.979 \\
(3.398)\end{array}$ \\
\hline \multicolumn{4}{|c|}{$\begin{array}{l}\text { Exogenous or instrumental } \\
\text { variables }\end{array}$} \\
\hline DSEX & female $=1$ & 0.561 & 0.500 \\
\hline AGE & Age (in years) & $\begin{array}{c}35.538 \\
(17.404)\end{array}$ & $\begin{array}{c}34.051 \\
(15.154)\end{array}$ \\
\hline NCHILD & Number of children & $\begin{array}{c}0.244 \\
(0.665)\end{array}$ & $\begin{array}{c}0.326 \\
(0.755)\end{array}$ \\
\hline CHILD6 & Household with preschool child & 0.041 & 0.051 \\
\hline MONTREAL & Montreal region & 0.401 & 0.424 \\
\hline BAS ST-LAUR & Region of Bas St-Laurent & 0.199 & 0.136 \\
\hline SINGLE & Single person household & 0.326 & 0.284 \\
\hline ONEPAR & One-parent household & 0.166 & 0.203 \\
\hline OTHD & $\begin{array}{l}\text { Other household situation } \\
\text { (roomate, grandparent, friend) }\end{array}$ & 0.124 & 0.161 \\
\hline PRIMEDU & Primary education & 0.114 & 0.055 \\
\hline COLLEDU & College education & 0.293 & 0.331 \\
\hline UNIVEDU & University education & 0.247 & 0.352 \\
\hline NLINC & Nonlabor income (Can \$) /100 & $\begin{array}{c}1.048 \\
(4.660)\end{array}$ & $\begin{array}{c}1.292 \\
(6.223)\end{array}$ \\
\hline RATION & $\begin{array}{l}\text { Feels constrained in } \\
\text { the number of hours of work } \\
\text { in regular sector }(\text { yes }=1 \text { ) }\end{array}$ & 0.397 & 0.496 \\
\hline REAC & $\begin{array}{l}\text { Reaction of own social circle } \\
\text { towards working in the underground } \\
\text { sector (does not disapprove }=1 \text { ) }\end{array}$ & 0.611 & 0.797 \\
\hline EXP & Years of experience & $\begin{array}{c}11.611 \\
(11.926)\end{array}$ & $\begin{array}{c}11.904 \\
(10.736)\end{array}$ \\
\hline INCAP & $\begin{array}{l}\text { Absence from work due to } \\
\text { sickness or accident }(\text { yes }=1)\end{array}$ & 0.211 & 0.241 \\
\hline
\end{tabular}

Standard errors are in parentheses.

Excluded categories: Quebec region; respondent living with parent(s); secondary education. 


\section{Table 3}

\section{Parameter Estimates of Expenditures on Irregular Goods and Services}

\begin{tabular}{lccccc}
\hline & \multicolumn{3}{c}{ Full sample } & \multicolumn{3}{c}{ Restricted sample } \\
& Tobit & $\begin{array}{c}\left(C_{u} \geq 0\right) \\
\text { NLLS }\end{array}$ & GMM & NLLS & GMM \\
\hline \multirow{2}{*}{ Intercept } & & & & & \\
& -4.118 & -4.927 & -0.993 & -1.225 & 1.933 \\
DSEX (Female = 1) & $(0.298)$ & $(1.072)$ & $(0.517)$ & $(0.666)$ & $(2.668)$ \\
& -0.085 & 0.274 & -0.038 & -0.290 & -0.703 \\
AGE & $(0.043)$ & $(0.206)$ & $(0.031)$ & $(0.089)$ & $(0.575)$ \\
& -24.81 & -63.33 & 18.84 & 12.15 & 29.81 \\
MONTREAL & $(13.92)$ & $(69.56)$ & $(13.14)$ & $(3.14)$ & $(19.76))$ \\
& -0.062 & -4.339 & -0.038 & -0.074 & -0.084 \\
BAS ST-LAUR & $(0.042)$ & $(0.564)$ & $(0.037)$ & $(0.092)$ & $(0.227)$ \\
log m /100 & -0.237 & -1.090 & -0.112 & -0.129 & -0.196 \\
& $(0.063)$ & $(0.479)$ & $(0.054)$ & $(0.140)$ & $(0.293)$ \\
$h_{r}$ & 3.285 & 4.305 & 1.060 & 1.871 & -2.784 \\
& $(0.319)$ & $(1.030)$ & $(0.515)$ & $(0.757)$ & $(3.038)$ \\
$h_{u}$ & 0.108 & 0.459 & 0.082 & 0.106 & 0.608 \\
& $(0.026)$ & $(0.100)$ & $(0.041)$ & $(0.056)$ & $(0.347)$ \\
$\sigma$ & 1.47 & 4.64 & 2.55 & 2.50 & 1.88 \\
& $(0.06)$ & $(0.029)$ & $(0.49)$ & $(0.13)$ & $(0.90)$ \\
& 0.317 & 0.724 & 0.032 & 0.315 & 0.747 \\
& $(0.004)$ & $(0.187)$ & $(0.136)$ & $(0.509)$ & $(0.589)$ \\
\hline \multirow{2}{*}{ log-likelihood } & & & & & \\
GMM value of function & 740.4 & & & & \\
NLLS value of function & & 1529.1 & & & \\
Number of observations & 1569 & 1569 & 1569 & 236 & 236 \\
\hline \hline
\end{tabular}

Standard errors are in parentheses.

Quebec region is the excluded variable.

Instruments: INTERCEPT, DSEX, AGE, AGE2, AGE3, NCHILD, CHILD6, MONTREAL, BAS ST-LAUR, SINGLE, ONEPAR, OTHD, PRIMEDU, COLLEDU, UNIVEDU, NLINC, NLINC2, RATION, REAC. 


\section{Table 4}

\begin{tabular}{cccl}
\multicolumn{3}{c}{ Specification Tests } \\
\hline & $\begin{array}{c}\text { Full } \\
\text { sample } \\
\left(C_{u} \geq 0\right)\end{array}$ & $\begin{array}{c}\text { Restricted } \\
\text { sample } \\
\left(C_{u}>0\right)\end{array}$ & Diagnostic \\
\hline $\begin{array}{c}\text { Hausman tests } \\
\text { GMM vs NLLS }\end{array}$ & 81.83 & 49.62 & $\begin{array}{l}\text { reject } H_{0} \\
\chi_{.05}^{2}(9)=16.92\end{array}$ \\
$\begin{array}{c}\text { GMM Tests } \\
\text { Hansen }\end{array}$ & 11.65 & 8.14 & $\begin{array}{l}\text { Do not reject } \\
\chi_{.05}^{2}(10)=18.31\end{array}$ \\
$\begin{array}{c}\beta_{u}^{h}=\beta_{r}^{h}=0: \\
\text { Wald } \\
\text { Newey-West }\end{array}$ & 28.12 & 14.18 & $\begin{array}{l}\text { reject } H_{0} \\
\text { reject } H_{0} \\
\chi_{.05}^{2}(2)=5.99\end{array}$ \\
$\beta_{u}^{h}=\beta_{r}^{h}:$ & 11.06 & 6.27 & $\begin{array}{l}\text { reject } \\
\text { Wald }\end{array}$ \\
\cline { 2 - 4 } & 15.40 & 7.45 & $\chi_{.05}^{2}(1)=3.84$ \\
\hline \hline
\end{tabular}

Table 5

Marginal Effects of Key Variables on the Consumption of Irregular Goods and Services

\begin{tabular}{lcc}
\hline & GMM Estimates & GMM Estimates \\
& Using Full Sample & Using Restricted Sample \\
\hline Log Disposable income & 106.04 & -170.0 \\
& $(205.57)$ & $(-85.1)$ \\
Hours of work, regular sector & 0.082 & 0.371 \\
& $(0.042)$ & $(0.153)$ \\
Hours of work, irregular sector & 2.548 & 1.149 \\
& $(0.497)$ & $(0.792)$ \\
\hline \hline
\end{tabular}

Standard errors are in parentheses. 


\section{Table 6}

\section{Sensitivity Analysis of GMM Estimates}

to the Choice of Instruments

\begin{tabular}{|c|c|c|c|c|}
\hline & $\begin{array}{c}\text { log of Disposable } \\
\text { income }\end{array}$ & $\begin{array}{l}\text { Hours of work, } \\
\text { regular sector }\end{array}$ & $\begin{array}{l}\text { Hours of work, } \\
\text { irregular sector }\end{array}$ & $\begin{array}{l}\text { GMM value } \\
\text { of function* }\end{array}$ \\
\hline \multicolumn{5}{|c|}{ Full SAMPle $\left(C_{u} \geq 0\right)$} \\
\hline \multicolumn{5}{|l|}{ Excluded: } \\
\hline Ration & $\begin{array}{l}135.2 \\
(90.5)\end{array}$ & $\begin{array}{c}0.116 \\
(0.061)\end{array}$ & $\begin{array}{l}2.65 \\
(0.059)\end{array}$ & 10.40 \\
\hline Non-Labour Income & $\begin{array}{l}170.0 \\
(80.5)\end{array}$ & $\begin{array}{c}0.057 \\
(0.040)\end{array}$ & $\begin{array}{l}2.06 \\
(0.049)\end{array}$ & 14.56 \\
\hline School dummies & $\begin{array}{l}105.3 \\
(71.0)\end{array}$ & $\begin{array}{c}0.167 \\
(0.083)\end{array}$ & $\begin{array}{c}2.85 \\
(0.72)\end{array}$ & 8.38 \\
\hline $\begin{array}{l}\text { Included: } \\
\text { Incap }\end{array}$ & $\begin{array}{l}105.4 \\
(55.5)\end{array}$ & $\begin{array}{c}0.084 \\
(0.048)\end{array}$ & $\begin{array}{l}2.58 \\
(0.052)\end{array}$ & 11.49 \\
\hline & \multicolumn{3}{|c|}{ RESTRICTED SAMPLE $\quad\left(C_{u}>0\right)$} & \\
\hline Excluded: & & & & \\
\hline Ration & $\begin{array}{l}-225.1 \\
(268.1)\end{array}$ & $\begin{array}{c}0.478 \\
(0.265)\end{array}$ & $\begin{array}{l}1.74 \\
(0.80)\end{array}$ & 6.17 \\
\hline Non-Labour Income & $\begin{array}{l}-148.0 \\
(632.0)\end{array}$ & $\begin{array}{c}0.616 \\
(0.594)\end{array}$ & $\begin{array}{c}1.88 \\
(1.11)\end{array}$ & 7.60 \\
\hline School dummies & $\begin{array}{l}-293.3 \\
(298.4)\end{array}$ & $\begin{array}{c}0.693 \\
(0.365)\end{array}$ & $\begin{array}{c}2.66 \\
(1.07)\end{array}$ & 6.20 \\
\hline $\begin{array}{l}\text { Included: } \\
\text { Incap }\end{array}$ & $\begin{array}{l}-248.0 \\
(288.2)\end{array}$ & $\begin{array}{c}0.608 \\
(0.369)\end{array}$ & $\begin{array}{c}1.87 \\
(0.92)\end{array}$ & 8.25 \\
\hline
\end{tabular}

Standard errors are in parentheses.

${ }^{*} H_{0}$ is accepted in all cases. 


\section{Table 7}

\begin{tabular}{|c|c|c|c|c|}
\hline \multicolumn{5}{|c|}{$\begin{array}{c}\text { Underestimation Bias on Undergrounc } \\
\text { Output Associated with a } 1 \% \\
\text { Decrease in Irregular Hours of Work }\end{array}$} \\
\hline$\overline{\eta^{s} \backslash \eta^{d}}$ & 1 & 1.5 & 2 & 3 \\
\hline \multirow[t]{2}{*}{0} & 1.00 & 0.306 & 0.181 & 0.100 \\
\hline & 1.00 & 0.497 & 0.330 & 0.198 \\
\hline \multirow[t]{2}{*}{0.5} & 1.00 & 0.335 & 0.207 & 0.119 \\
\hline & 1.00 & 0.542 & 0.377 & 0.237 \\
\hline \multirow[t]{2}{*}{1} & 1.00 & 0.351 & 0.223 & 0.133 \\
\hline & 1.00 & 0.568 & 0.406 & 0.263 \\
\hline \multirow[t]{2}{*}{1.5} & 1.00 & 0.361 & 0.234 & 0.142 \\
\hline & 1.00 & 0.584 & 0.426 & 0.283 \\
\hline \multirow[t]{2}{*}{2} & 1.00 & 0.368 & 0.242 & 0.149 \\
\hline & 1.00 & 0.596 & 0.440 & 0.297 \\
\hline \multirow[t]{2}{*}{3} & 1.00 & 0.378 & 0.252 & 0.159 \\
\hline & 1.00 & 0.611 & 0.460 & 0.316 \\
\hline
\end{tabular}

First line : $\bar{\eta}=0.166$ (calculated from GMM estimates based on restricted sample).

Second line : $\bar{\eta}=0.37$ (calculated from GMM estimates based on full sample). 
Figure 1

Distribution of Expenditures on Irregular Commodities

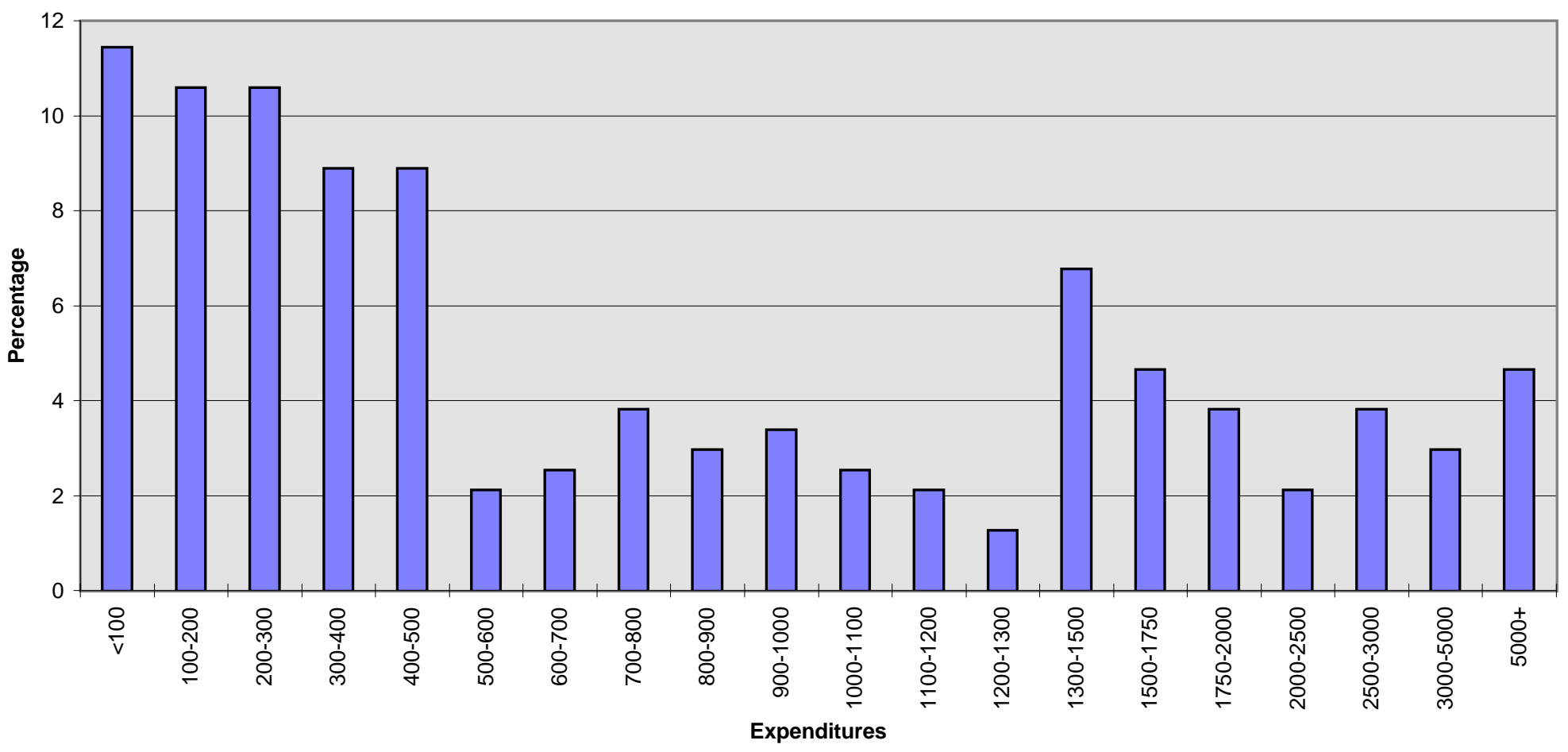




\section{Liste des publications au CIRANO}

\section{Cahiers CIRANO / CIRANO Papers (ISSN 1198-8169)}

96c-1 Peut-on créer des emplois en réglementant le temps de travail ? / Robert Lacroix

95c-2 Anomalies de marché et sélection des titres au Canada / Richard Guay, Jean-François L'Her et Jean-Marc Suret

95c-1 La réglementation incitative / Marcel Boyer

94c-3 L'importance relative des gouvernements : causes, conséquences et organisations alternative / Claude Montmarquette

94c-2 Commercial Bankruptcy and Financial Reorganization in Canada / Jocelyn Martel

94c-1 Faire ou faire faire : La perspective de l'économie des organisations / Michel Patry

Série Scientifique / Scientific Series (ISSN 1198-8177)

97s-30 Taxation or Regulation: Looking for a Good Anti-Smoking Policy / Paul Leclair et Paul Lanoie

97s-29 Optimal Trading Mechanisms with Ex Ante Unidentified Traders / Hu Lu et Jacques Robert

97s-28 Are Underground Workers More Likely To Be Underground Consumers? / Bernard Fortin, Guy Lacroix et Claude Montmarquette

97s-27 Analyse des rapports entre donneurs d'ordres et sous-traitants de l'industrie aérospatiale nord-américaine / Mario Bourgault

97s-26 Industrie aérospatiale nord-américaine et performance des sous-traitants : Écarts entre le Canada et les États-Unis / Mario Bourgault

97s-25 Welfare Benefits, Minimum Wage Rate and the Duration of Welfare Spells: Evidence from a Natural Experiment in Canada / Bernard Fortin et Guy Lacroix

97s-24 Incentive Effects of Public Insurance Programs on the Occurence and the Composition of Workplace Injuries / Denis Bolduc, Bernard Fortin, France Labrecque et Paul Lanoie

97s-23 Contrat dynamique de partage de risque avec contraintes d'engagement et épargne / Karine Gobert et Michel Poitevin

97s-22 Comparing Open-Loop with Markov Equilibria in a Class of Differential Games / Ngo Van Long, Koji Shimomura et Harataka Takahashi

97s-21 Efficiency Inducing Taxation for Polluting Oligopolists / Hassan Benchekroun et Ngo Van Long

97s-20 Tests of Conditional Asset Pricing Models in the Brazilian Stock Market / Marco Bonomo et René Garcia

\footnotetext{
* Vous pouvez consulter la liste complète des publications du CIRANO et les publications elles-mêmes sur notre site World Wide Web à l'adresse suivante :

http://www.cirano.umontreal.ca/publication/page1.html
} 